\title{
Women and Stroke: Different, yet Similar
}

\author{
Nandini Mitta ${ }^{a}$ Sapna Erat Sreedharan ${ }^{a}$ Sankara P. Sarma ${ }^{b}$ \\ Padmavathy N. Sylaja ${ }^{a}$ \\ aDepartment of Neurology, Sree ChitraTirunal Institute for Medical Sciences and Technology, Comprehensive \\ Stroke Care Programme, Trivandrum, India; 'bree ChitraTirunal Institute for Medical Sciences and Technology, \\ Achutha Menon Centre for Health Science Studies, Trivandrum, India
}

\section{Keywords}

Gender differences · Ischemic stroke · Stroke subtype ·

Stroke severity - Outcome

\begin{abstract}
Background: The impact of gender on acute ischemic stroke, in terms of presentation, severity, etiology, and outcome, is increasingly getting recognized. Here, we analyzed the gender-related differences in etiology and outcome of ischemic stroke in South India. Methods: Patients with first ever ischemic stroke within 1 week of onset presenting to the Comprehensive Stroke Care Centre, Sree Chitra Tirunal Institute for Medical Sciences and Technology, Trivandrum, India, were included in our study. Clinical and risk factor profile was documented. The stroke severity was assessed using the National Institutes of Health Stroke Scale (NIHSS) at onset, and stroke subtype classification was done using Trial of Org 10172 in Acute Ischemic Stroke criteria. The 3-month functional outcome was assessed using the modified Rankin Scale (mRS) with excellent outcome defined as an $m R S \leq 2$. Results: Of the 742 patients, 250 (33.7\%) were females. The age, clinical profile, and rate of reperfusion therapies did not differ between the genders. Women suffered more severe strokes (mean NIHSS 9.5 vs. 8.4, $p=0.03$ ). While large artery
\end{abstract}

karger@karger.com www.karger.com/cee

Karger $\stackrel{\text { ' }}{5}$

GOPEN ACCESS
(C) 2021 The Author(s).

Published by S. Karger AG, Basel

This is an Open Access article licensed under the Creative Commons Attribution-NonCommercial-4.0 International License (CC BY-NC) (http://www.karger.com/Services/OpenAccessLicense), applicable to the online version of the article only. Usage and distribution for commercial purposes requires written permission. atherosclerosis was more common in men $(21.3 \%$ vs. $14.8 \%$, $p=0.03$ ), cardioembolic strokes secondary to rheumatic heart disease were more common in women $(27.2 \%$ vs. $19.7 \%, p=0.02)$. Men had a better 3-month functional outcome compared to women (68.6\% vs. $61.2 \%, p=0.04$ ), but was not statistically significant after adjusting for confounders. Conclusion: Our data, from a single comprehensive stroke unit from South India, suggest that stroke in women are different, yet similar in many ways to men. Guidelinebased treatment can result in comparable short-term outcomes, irrespective of admission stroke severity.

(C) 2021 The Author(s).

Published by S. Karger AG, Basel

\section{Introduction}

Gender differences in ischemic stroke are increasingly getting reported. Although men are more prone to vascular diseases, the risk is not uniform across all ages. Studies on animal stroke models have shown a protective role of female sex hormones on ischemic injury $[1,2]$. These biological differences in stroke risk are seen in epidemiological studies also, with a steep rise in stroke incidence after 60s in women and surpassing men in the 70s [3]. Among stroke survivors, women tend to be older and 
have more severe strokes and less favorable outcome [4]. In addition to biological factors, the differences could also be augmented by disparity in access to acute and preventive stroke therapies and rehabilitation services, which may be relevant in low- and middle-income countries [5].

There is paucity of data on the impact of gender on ischemic stroke from low- and middle-income countries, including India which accounts for four-fifths of all new incident strokes across the world [6]. With increasing lifespan and high prevalence of lifestyle diseases, low- and middle-income countries like India are likely to have more women with stroke and its sequelae in the coming years. There are hardly any data focusing on gender differences in ischemic stroke from India [7]. We believe identification of these differences will aid in planning treatment and prevention strategies. Hence, we undertook this study to understand the gender differences in risk factor profile, clinical presentation, stroke subtype, and outcome in our population.

\section{Materials and Methods}

All first ever ischemic stroke patients aged 18 years or above admitted in the Comprehensive Stroke Care unit, Department of Neurology, Sree Chitra Tirunal Institute for Medical Sciences and Technology, Trivandrum, South India, within 1 week of symptom onset were included in the study. The study period was from January 2014 to December 2017 (4 years). Patients with transient ischemic attack, pre-stroke modified Rankin score 3 or above, hemorrhagic strokes, and cerebral venous thrombosis were excluded. Their demographic and clinical details and risk factor status were extracted from medical records. Hypertension was defined as BP $>130 / 80 \mathrm{~mm} \mathrm{Hg}$ persisting $>48 \mathrm{~h}$ of acute stroke or prior use of antihypertensives. Diabetes mellitus was defined as fasting plasma glucose $>126 \mathrm{mg} / \mathrm{dL}$ and postprandial or random blood sugar over $200 \mathrm{mg} / \mathrm{dL}$ and/or glycosylated hemoglobin $>6.5 \%$ or patient being on blood sugar-lowering medications. Hyperlipidemia was defined as fasting cholesterol $>200 \mathrm{mg} / \mathrm{dL}$ and/or LDL-C $>100 \mathrm{mg} /$ $\mathrm{dL}$, detected before or during ischemic stroke. Those with a history of current/recent usage of tobacco within 3 months of stroke were classified as smokers. History of regular alcohol intake (at least 3 days a week) was also taken. The stroke severity was assessed using the National Institutes of Health stroke scale (NIHSS) at onset [8]. The stroke subtype classification was done using TOAST (Trial of Org 10172 in Acute Ischemic Stroke) Criteria [9]. Details of acute reperfusion therapies, its complications, and discharge outcome were also collected. Three-month functional outcome was assessed using the modified Rankin scale (mRS), and excellent outcome was defined as an $\mathrm{mRS} \leq 2$. In those patients where a stroke clinic follow-up was missing, a telephonic follow-up for assessing functional status and any recurrent events was also done.

Statistical analysis was performed using SPSS version 17 software (SPSS Inc., Chicago, IL, USA). For univariate analysis, continuous variables were studied using Student $t$ tests and for categorical variables, Pearson $\chi^{2}$ tests as well as Fisher's exact tests were used. A multivariate logistic regression analysis of all variables with statistical significance on univariate analysis was performed, and those parameters with a $p$ value of $<0.05$ were considered statistically significant.

\section{Results}

Of the 1,851 patients admitted with stroke during the study period, 742 who satisfied the inclusion criteria were included in the study. Majority were men (492 M:250 F) with mean age $59 \pm 12.9$ years. Baseline demographic and clinical characteristics are given in Table 1. Comparing the genders, hyperlipidemia and valvular heart disease were more frequently seen in females while tobacco and alcohol use were exclusively seen in male patients. Women tended to have more severe strokes at admission.

Of the study cohort, 3-month follow-up was available in 729 patients (98.24\%). Men had a more favorable outcome at 3 months on univariate analysis ( $p$ value $=0.046$ ). However, on multivariate analysis, age, admission NIHSS, diabetic status, and thrombolysis remained independent predictors of short-term outcome (Table 2) and gender failed to show an independent association. When outcome predictors for both genders were looked into, we found that admission NIHSS and thrombolytic therapy continued to show independent association in both, while DM was significant in only women (Tables 3,4 ).

\section{Discussion}

In our hospital-based cohort, women were slightly older than men. This is in line with the literature [10-12] and can be explained by the impact of age and menopause on vascular risk. Mean age of stroke in our cohort was comparable to other epidemiological and hospital-based studies on stroke from India, where it was reported as below 60 years of age $[13,14]$. This is significantly lower than what is reported from Chinese and Western population and can be explained by the higher reported prevalence of vascular risk factors in young Indians contributing to vascular disease burden $[15,16]$. Among the vascular risk factors, we found that elevated lipid levels were more found in women, an observation previously reported from India [7]. This is contradictory to reports from the Western world, where higher prevalence of diabetes, dyslipidemia, and peripheral vascular disease was reported in male stroke survivors $[10,11]$. No statistically significant gender differences were noted for clinical features at presentation. However, looking at the risk factor 
Table 1. Comparison of gender differences in risk factor profile, clinical presentation, stroke subtype, and outcome
Table 2. Multivariate analysis of factors predicting 3-month functional outcome

\begin{tabular}{|c|c|c|c|}
\hline Variable & Men & Women & $p$ value \\
\hline Age (mean [SD]), years & $59.8(12.7)$ & $60.1(13.3)$ & 0.775 \\
\hline Hypertension, $n$ (\%) & $322(65.4)$ & $165(66)$ & 0.881 \\
\hline Diabetes, $n(\%)$ & $252(51.2)$ & $133(53.2)$ & 0.610 \\
\hline Hyperlipidemia, $n$ (\%) & $192(39)$ & $146(58.6)$ & 0.000 \\
\hline Valvular heart disease, $n(\%)$ & $20(4.1)$ & $32(12.8)$ & 0.000 \\
\hline Nonvalvular atrial fibrillation, $n(\%)$ & $23(4.7)$ & $9(3.6)$ & 0.496 \\
\hline Coronary artery disease, $n(\%)$ & $136(27.6)$ & $29(11.6)$ & 0.000 \\
\hline Tobacco smoking, $n(\%)$ & $146(29.6)$ & $0(0.0)$ & 0.000 \\
\hline Alcohol usage, $n(\%)$ & $149(30.2)$ & $0(0.0)$ & 0.000 \\
\hline \multicolumn{4}{|l|}{ Clinical presentation } \\
\hline Weakness, $n(\%)$ & $372(75.6)$ & $197(78.8)$ & 0.331 \\
\hline Aphasia, $n(\%)$ & $121(24.6)$ & $70(28)$ & 0.316 \\
\hline Numbness, $n(\%)$ & $35(7.1)$ & $18(7.2)$ & 0.966 \\
\hline Blood sugar at admission, mean ( \pm SD) & $161(75.8)$ & $168(73.5)$ & 0.180 \\
\hline $\mathrm{HbA} 1 \mathrm{C}$, mean ( $\pm \mathrm{SD})$ & $7.02(1.68)$ & $7.27(1.88)$ & 0.078 \\
\hline S. total cholesterol, mean ( \pm SD) & $181(52.2)$ & $196(50.8)$ & 0.000 \\
\hline \multicolumn{4}{|l|}{ Stroke subtype } \\
\hline Large artery atherosclerosis, $n$ (\%) & $105(21.3)$ & $37(14.8)$ & 0.032 \\
\hline Cardioembolic, $n(\%)$ & $97(19.7)$ & $68(27.2)$ & 0.020 \\
\hline Valvular heart disease, $n(\%)$ & $12(12.4)$ & $32(47)$ & 0.0013 \\
\hline Nonvalvular atrial fibrillation, $n(\%)$ & $50(51.5)$ & $23(33.8)$ & 0.024 \\
\hline Others & $35(36.08)$ & $23(33.8)$ & 0.92 \\
\hline Lacunar, $n(\%)$ & $102(20.7)$ & $47(18.8)$ & 0.535 \\
\hline Admission NIHSS, mean (SD) & $8.46(6.62)$ & $9.54(6.91)$ & 0.039 \\
\hline Time from onset to thrombolysis, mean $( \pm S D)$, min & $194(76.2)$ & $190(85.0)$ & 0.755 \\
\hline Rate of thrombolysis, $n(\%)$ & $88(17.8)$ & $42(16.8)$ & 0.817 \\
\hline 1. Intravenous & $64(72.7)$ & $27(64.3)$ & 0.326 \\
\hline 2. Mechanical thrombectomy & $15(17.0)$ & $9(21.4)$ & 0.547 \\
\hline 3. Bridging & $9(10.3)$ & $6(14.3)$ & 0.561 \\
\hline Symptomatic ICH after thrombolysis & $13(14.7)$ & $0(0.0)$ & 0.005 \\
\hline In-hospital mortality, $n$ (\%) & $16(3.3)$ & $12(4.8)$ & 0.296 \\
\hline $\mathrm{mRS}$ at 3 months, $1-2, n(\%)$ & $326(68.6)$ & $148(61.2)$ & 0.046 \\
\hline Stroke recurrence at 3 months, $n$ (\%) & $14(2.8)$ & $2(0.8)$ & 0.070 \\
\hline 3-month mortality, $n$ (\%) & $31(6.5)$ & $21(8.7)$ & 0.294 \\
\hline
\end{tabular}

\begin{tabular}{lllll}
\hline \multirow{2}{*}{$\begin{array}{llll}\text { Variable } \\
\text { Odds ratio }\end{array}$} & \multicolumn{2}{l}{$95 \%$ confidence interval } & \multirow{2}{*}{$p$ value } \\
\cline { 3 - 4 } & & upper limit & lower limit & \\
\hline Age & $\mathbf{1 . 0 2 2}$ & $\mathbf{1 . 0 0 4}$ & $\mathbf{1 . 0 3 9}$ & $\mathbf{0 . 0 1 4}$ \\
Sex & 1.152 & 0.745 & 1.779 & 0.525 \\
Admission NIHSS & $\mathbf{1 . 2 9 3}$ & $\mathbf{1 . 2 4 0}$ & $\mathbf{1 . 3 4 8}$ & $\mathbf{0 . 0 0 0}$ \\
Hypertension & 0.990 & 0.628 & 1.559 & 0.964 \\
Diabetes mellitus & $\mathbf{1 . 6 6 1}$ & $\mathbf{1 . 0 9 9}$ & $\mathbf{2 . 5 1 3}$ & $\mathbf{0 . 0 1 6}$ \\
Hyperlipidemia & 0.922 & 0.613 & 1.385 & 0.694 \\
CAD & 0.642 & 0.384 & 1.073 & 0.091 \\
Valvular heart disease & 0.840 & 0.344 & 2.050 & 0.702 \\
Large vessel atherosclerosis & 0.992 & 0.537 & 1.831 & 0.979 \\
Cardioembolic & 1.337 & 0.673 & 2.658 & 0.407 \\
Rate of thrombolysis & $\mathbf{5 . 4 7 2}$ & $\mathbf{3 . 0 0 1}$ & $\mathbf{9 . 9 7 5}$ & $\mathbf{0 . 0 0 0}$ \\
\hline
\end{tabular}


Table 3. Multivariate analysis of 3-month outcome predictors for male gender

\begin{tabular}{|c|c|c|c|c|}
\hline \multirow[t]{2}{*}{ Variable } & \multirow[t]{2}{*}{ Odds ratio } & \multicolumn{2}{|c|}{$95 \%$ confidence interval } & \multirow[t]{2}{*}{$p$ value } \\
\hline & & upper limit & lower limit & \\
\hline Age & 2.057 & 0.659 & 6.419 & 0.214 \\
\hline Admission NIHSS & 1.292 & 1.226 & 1.360 & 0.000 \\
\hline Hypertension & 0.962 & 0.559 & 1.656 & 0.889 \\
\hline Diabetes mellitus & 1.383 & 0.824 & 2.322 & 0.220 \\
\hline Hyperlipidemia & 0.910 & 0.544 & 1.524 & 0.721 \\
\hline CAD & 0.599 & 0.331 & 1.084 & 0.090 \\
\hline Large vessel atherosclerosis & 1.054 & 0.497 & 2.234 & 0.891 \\
\hline Cardioembolic & 1.940 & 0.827 & 4.552 & 0.128 \\
\hline Rate of thrombolysis & 4.070 & 1.963 & 8.438 & 0.000 \\
\hline
\end{tabular}

\begin{tabular}{lllll}
\hline \multirow{2}{*}{ Variable } & \multirow{2}{*}{ Odds ratio } & \multicolumn{2}{l}{$95 \%$ confidence interval } & \multirow{2}{*}{$p$ value } \\
\cline { 3 - 4 } & & upper limit & lower limit & \\
\hline Age & 6.051 & 0.878 & 41.679 & 0.068 \\
Admission NIHSS & $\mathbf{1 . 3 0 9}$ & $\mathbf{1 . 2 1 4}$ & $\mathbf{1 . 4 1 2}$ & $\mathbf{0 . 0 0 0}$ \\
Hypertension & 1.033 & 0.449 & 2.376 & 0.939 \\
Diabetes mellitus & $\mathbf{2 . 2 5 7}$ & $\mathbf{1 . 0 8 8}$ & $\mathbf{4 . 6 8 1}$ & $\mathbf{0 . 0 2 9}$ \\
Hyperlipidemia & 0.826 & 0.410 & 1.664 & 0.593 \\
Valvular heart disease & 0.807 & 0.213 & 3.053 & 0.752 \\
Large vessel atherosclerosis & 1.287 & 0.424 & 3.913 & 0.656 \\
Cardioembolic & 1.041 & 0.302 & 3.593 & 0.949 \\
Rate of thrombolysis & $\mathbf{1 0 . 3 9 3}$ & $\mathbf{3 . 4 5 5}$ & $\mathbf{3 1 . 2 6 0}$ & $\mathbf{0 . 0 0 0}$ \\
\hline
\end{tabular}

Table 4. Multivariate analysis of 3-month outcome predictors for female stroke patients control in our cohort, women had less glycemic control compared to men at admission.

Cardioembolism was the single major etiological subgroup of stroke in women in our study $(27.2 \%$ vs. $19.7 \%$, $p$ value 0.02 ) while large artery atherosclerosis was the major causation in men $(21.3 \%$ vs. $14.1 \%$, $p$ value 0.032$)$. Among the cardioembolic strokes, valvular heart disease was significantly associated with women. Studies from countries with low prevalence of rheumatic valvular heart disease (RHD) have shown that older women with stroke have higher frequency of nonvalvular atrial fibrillation [12]. The prevalence rate of rheumatic heart disease in our study group was $4.6 \%$ of the entire study population which is similar to that observed in the Indo-US Collaborative Stroke Project [13]. Higher female predilection for RHD and stroke has been reported previously also, which can range from 33.5 to $83 \%$ in many hospital-based series [17]. In our series, RHD contributed to $32.4 \%$ of total cardioembolic strokes in females. Contrary to prior reports, we found nonvalvular atrial fibrillation more in men $[12,18]$. Other causes of cardioembolic stroke (re- cent extensive anterior wall myocardial infarction, left ventricular or atrial thrombus, and severe left ventricular dysfunction/congestive heart failure) were comparable between men and women.

Men suffered more atherothrombotic strokes, probably secondary to higher frequency of smoking and coexistent coronary disease in our population and has been reported previously [12]. We could not come across any similar studies on gender differences in stroke subtypes from India. Women suffered more severe strokes which has been reported earlier [17, 19] while a few studies found little or no significant sex difference in stroke severity [20]. This increased stroke severity may be partly explained by higher prevalence of cardioembolic strokes in our study cohort.

Regarding treatment aspects, there was no significant difference in the door to needle time between sexes. Some studies have shown that women are less likely to be admitted to the hospital within the first $3 \mathrm{~h}$ of stroke onset than men and have more delay in door to needle times [5] while some failed to find an association [21]. Although 
there are reports that women are less likely to receive alteplase than men $[22,23]$, our rates of thrombolysis were similar which might be due to the higher literacy rate of Kerala population with increased stroke awareness and early presentation leading to timely access to treatment [24].

Although post-stroke outcomes were less favorable for women, gender failed to show a statistically significant impact on short-term outcome in our cohort. Conflicting reports on impact of female gender on outcome can be found in the literature $[7,11]$. The reasons for this might be factors like older age, greater stroke severity, and higher rate of in-hospital medical complications reported in women in most of the studies across the world. This can have an independent impact on outcome, beyond the effect of gender. Previous authors have reported the significant association of age, NIHSS, previous stroke, DM, and thrombolytic therapy with short-term outcome [25, 26 , which was comparable to the findings from our cohort as well.

The strengths of our study are large sample size, with patients from 2 southern states of India included over a 4 -year period, and availability of 3-month follow-up data of $>90 \%$ of the patients. Uniform etiological evaluation was done in all patients, including vessel imaging, transthoracic echo, and rhythm monitoring, which adds to the strength of the etiological subtype of stroke.

However, the study has certain limitations. Being a retrospective single-center hospital-based study, our results cannot be generalized to Indian population. Being a comprehensive stroke care center, there is always a referral and admission bias with minor strokes often getting evaluated on an outpatient basis, so our study cohort cannot fully represent stroke population at large. Pre-stroke disability (modified Rankin scale 3 or above) in itself can limit patient's access to treatment like thrombolysis, secondary stroke prevention strategies, and post-stroke rehabilitation regardless of gender. This was the reason patients with pre-existing disabilities were excluded from the current study.

Nonetheless, our data provide valuable insights into the gender differences of stroke in South India. With regard to stroke subtype, we found large vessel atherosclerosis to be more common in men and cardioembolic strokes, secondary to rheumatic heart disease, more in women. Although women were older, suffered more severe strokes, and had higher in-hospital mortality, gender failed to be an independent predictor for short-term outcome. In older stroke survivors, stroke severity at admission and administration of thrombolytic therapy predict- ed short-term outcome, for both men and women, indicating that acute stroke care strategies need to address both genders equally.

\section{Statement of Ethics}

The conduct of the study was approved by the Institutional Ethics Committee (IEC/SCT/1153). Since this was a retrospective study, waiver for written individual patient consent was obtained from the Institutional Ethics Committee.

\section{Conflict of Interest Statement}

The authors have no conflicts of interest to report.

\section{Funding Sources}

The authors have no funding sources to report pertaining to this study.

\section{Author Contributions}

Nandini Mitta (first author) was involved in conceptualization of the study, data collection, and writing of the first draft. Sapna Erat Sreedharan (corresponding author) was involved in conceptualization of the study and writing the final draft of the manuscript. Sarma (third author) performed statistical analysis and revision of the final draft. P.N. Sylaja (fourth author) was involved in conceptualization of the study and writing and revision of the final draft of the manuscript.

\section{Data Availability Statement}

All the data generated and analyzed during this study are included in this article, and further enquiries can be directed to the corresponding author.

\section{References}

$$
\begin{aligned}
& 1 \text { Turtzo LC, McCullough LD. Sex-specific re- } \\
& \text { sponses to stroke. Future Neurol. 2010;5:47- } \\
& 59 . \\
& 2 \text { Wilson ME. Stroke: understanding the differ- } \\
& \text { ences between males and females pflugers. } \\
& \text { Arch. 2013 May;465(5):595-600. } \\
& 3 \text { Petrea RE, Beiser AS, Seshadri S, Kelly-Hayes } \\
& \text { M, Kase CS, Wolf PA. Gender differences in } \\
& \text { stroke incidence and poststroke disability in } \\
& \text { the Framingham heart study. Stroke. 2009;40: } \\
& \text { 1032-7. } \\
& 4 \text { Gall SL, Donnan G, Dewey HM, Macdonell R, } \\
& \text { Sturm J, Gilligan A, et al. Sex differences in } \\
& \text { presentation, severity, and management of } \\
& \text { stroke in a population-based study. Neurolo- } \\
& \text { gy. 2010;74(12):975-81. }
\end{aligned}
$$


5 Menon SC, Pandey DK, Morgenstern LB. Critical factors determining access to acute stroke care [Internet]. Neurology. 1998;51: 427-32.

6 Krishnamurthi RV, Feigin VL, Forouzanfar $\mathrm{MH}$, Mensah GA, Connor M, Bennett DA, et al. Global Burden of Diseases, Injuries, Risk Factors Study 2010 (GBD 2010); GBD Stroke Experts Group. Global and regional burden of first-ever ischaemic and haemorrhagic stroke during 1990-2010: findings from the Global Burden of Disease Study 2010. Lancet Glob Health. 2013 Nov; 1(5):e259-81.

7 Kaur P, Pandian J, Singh G, Bansal R, Paul B, Singla $\mathrm{M}$, et al. Gender difference in stroke: are they different in India? (P1.261). Neurology. 2016 Apr 5;86(16 Supplement):P1.261.

8 Meyer BC, Hemmen TM, Jackson CM, Lyden PD. Modified national institutes of health stroke scale for use in stroke clinical trials: prospective reliability and validity. Stroke. 2002;33:1261-6.

9 Adams HP Jr, Bendixen BH, Kappelle LJ, Biller J, Love BB, Gordon DL, et al. Classification of subtype of acute ischemic stroke. Definitions for use in a multicenter clinical trial. TOAST. Trial of Org 10172 in acute stroke treatment. Stroke. 1993 Jan;24(1):35-41.

10 Di Carlo A, Lamassa M, Baldereschi M, Pracucci G, Basile AM, Wolfe CD, et al. Sex differences in the clinical presentation, resource use, and 3-month outcome of acute stroke in Europe: data from a multicenter multinational hospital-based registry. Stroke. 2003 May; 34(5):1114-9.

11 Kapral MK, Fang J, Hill MD, Silver F, Richards J, Jaigobin C, et al. Sex differences in stroke care and outcomes: results from the registry of the Canadian stroke network. Stroke. 2005 Apr;36(4):809-14.
12 Roquer J, Campello AR, Gomis M. Sex differences in first-ever acute stroke [Internet]. Stroke. 2003;34:1581-5.

13 Sylaja PN, Pandian JD, Kaul S, Srivastava MVP, Khurana D, Schwamm LH, et al. Ischemic stroke profile, risk factors, and outcomes in India: the Indo-US collaborative stroke project. Stroke. 2018 Jan;49(1):219-22.

14 Kalkonde YV, Sahane V, Deshmukh MD, Nila S, Mandava P, Bang A. High prevalence of stroke in rural Gadchiroli, India: a community-based study. Neuroepidemiology. 2016; 46:235-9.

15 Feigin VL, Lawes CM, Bennett DA, BarkerCollo SL, Parag V. Worldwide stroke incidence and early case fatality reported in 56 population-based studies: a systematic review. Lancet Neurol. 2009;8:355-69.

16 Tsai CF, Thomas B, Sudlow CL. Epidemiology of stroke and its subtypes in Chinese vs white populations: a systematic review. Neurology. 2013;81:264-72.

17 Wang D, Liu M, Lin S, Hao Z, Tao W, Chen $\mathrm{X}$, et al. Stroke and rheumatic heart disease: a systematic review of observational studies [Internet]. Clin Neurol Neurosurg. 2013;115: 1575-82.

18 Yao XY, Lin Y, Geng JL, Sun YM, Chen Y, Shi GW, et al. Age- and gender-specific prevalence of risk factors in patients with first-ever ischemic stroke in China [Internet]. Stroke Res Treat. 2012;2012:1-6.

19 Phan HT, Reeves MJ, Blizzard CL, Thrift AG, Cadilhac DA, Sturm J, et al. Sex differences in severity of stroke in the INSTRUCT Study: a meta-analysis of individual participant data. J Am Heart Assoc. 2019;8(1):e010235.
20 Barrett KM, Brott TG, Brown RD, Frankel MR, Worrall BB, Silliman SL, et al. Sex differences in stroke severity, symptoms, and deficits after first-ever ischemic stroke [Internet]. J Stroke Cerebrovasc Dis. 2007;16: 34-9.

21 Knauft W, Chhabra J, McCullough LD. Emergency department arrival times, treatment, and functional recovery in women with acute ischemic stroke [Internet]. J Womens Health. 2010;19:681-8

22 Reid JM, Dai D, Gubitz GJ, Kapral MK, Christian C, Phillips SJ. Gender differences in stroke examined in a 10-year cohort of patients admitted to a Canadian teaching hospital [Internet]. Stroke. 2008;39:1090-5.

23 Srivastava AK, Prasad K. A study of factors delaying hospital arrival of patients with acute stroke. Neurol India. 2001 Sep;49(3): 272-6.

24 Census of India 2011 State of literacy of ruralurban population Chapter VI Page 106 accessed online www.censusindia.gov.in on 20212206

25 Lorenzano S, Ahmed N, Falcou A, Mikulik R, Tatlisumak T, Roffe C, et al. Does sex influence the response to intravenous thrombolysis in ischemic stroke?: answers from safe implementation of treatments in stroke-international stroke thrombolysis register. Stroke. 2013 Dec;44(12):3401-6.

26 Meyer MJ, Pereira S, McClure A, Teasell R, Thind A, Koval J, et al. A systematic review of studies reporting multivariable models to predict functional outcomes after post-stroke inpatient rehabilitation [Internet]. Disabil Rehabil. 2015;37:1316-23. 